CRIME E LOUCURA: O APARECIMENTO DO MANICÔMIO JUDICIÁRIO NA PASSAGEM DO SÉCU LO. Sérgio Carrara. Rio de J aneiro: Eduerj/São Paulo: Edusp, 1998, 227 pp.

ISBN 85-85-88881-2

Loucura e sangue: a complexa relação entre crime e doença mental

No excelente Tributo a Vênus: A Luta contra a Sífilis no Brasil - da Passagem do Século aos Anos 40, Sérgio Carrara mostrou as numerosas e complexas injunções que caracterizam, em termos de saúde pública, o combate a uma doença estigmatizante. Trata-se da tese de doutoramento do autor. Contudo, esta não era a sua primeira incursão no terreno em que se cruzam, nas palavras de Peter Gay, a moralidade, a medicina e a lei; tal já havia acontecido em sua tese de mestrado, agora publicada sob forma de livro (Crime eLoucura: O Aparecimento do Manicômio Judiciário na Passagem do Século), publicado em 1998 graças a uma exemplar colaboração entre as editoras da Universidade do Estado do Rio de Janeiro (Eduerj) e da Universidade de São Paulo (Edusp). A obra está dividida em três capítulos, que correspondem a três partes bem distintas mas complementares, precedidas de uma apresentação do professor Peter Fry, que introduziu o autor ao tema.

Na primeira parte, Carrara narra a sua experiência no Manicômio Judiciário do Rio de Janeiro, atual Manicômio Judiciário Heitor Carrilho (ou, abreviadamente, MJ), no qual foi feita a pesquisa sugerida por Peter Fry. Há aqui um componente autobiográfico que impressiona pela autenticidade. Em princípio, o trabalho seria centralizado nos arquivos da instituição; de fato, porém, Carrara acabou participando, como observador, no cotidiano da instituição, sob muitos aspectos sui generis. Como diz o autor: “O MJ se caracteriza fundamentalmente por ser ao mesmo tempo um espaço prisi onal e asi lar, peni tenciário e hospi talar. Prenhe de conseqüências práticas, a diferença entre asi lo e prisão, visível através do MJ, está amplamente ancorada nas defi nições opostas que mantemos a respei to do estatuto jurídico-moral dos habitantes decada uma das instituições. Para a prisão enviamos culpados; o hospital ou o hospício recebem inocentes" (p. 27). O MJ é uma instituição híbrida, um hospital-prisão ou uma prisão-hospital. Conta com dois tipos de equipes: guardas e terapeutas. A relação entre ambas as equipes, diz Carrara, está longe de ser amistosa. Os terapeutas acusavam os guardas, que raramente apareciam nas reuniões da equipe terapêutica, de "não compreenderem o caráter médi co da insti tui ção e detratarem os internos como presos comuns" (p. 33). Mas os guardas permaneciam mais tempo no local e tinham um contato mais imediato e mais constante com os internos, desenvolvendo-se uma espécie de simbiose entre eles. Uma psicóloga pretendia denunciar ao diretor um guarda que maltratara um paciente, mas foi ameaçada por outro paciente: "sedenunciar os meus PMS, a senhora équele va coronhada" (p. 35).

Cisões institucionais como esta não são raras. Em hospitais, por exemplo, pode haver conflito entre técnicos e administradores. Nos órgãos de saúde, tal conflito pode, ademais, envolver elementos políticos. Mas, como bem sublinha Carrara, não se trata de uma "alergia" grupal; o que temos aí são concepções diferentes. Tanto isto é verdade, que a hostilidade entre terapeutas e guardas corresponde à tensão entre juízes e peritos médicos-psiquiatras. A hostilidade e a tensão acabavam tendo reflexos no cotidiano institucional. A controvérsia, por vezes, verificava-se dentro das próprias equipes. Por exemplo, diante da proposta de um local onde os internados pudessem receber parceiros(as) sexuais, os terapeutas reagiam de forma diferente, al guns apoiando, outros opondo-se, receosos de possível violência (p. 37)

Dessas observações, nasceu a questão básica que Sérgio Carrara aborda e que consiste em “saber o porquê,dentreas várias estruturas insti tucionais possivel mente capazes de exercer tal função ou responder a tal necessi dade, surgi u o complicado perfil de um asilo criminal". Para responder a tal pergunta, utilizou uma metodologia que conjuga as visões antropológica e histórica. É o estudo daquilo que se denomina 'aldeia-arquivo', a 'aldeia' sendo um território preferido por antropólogos e o 'arquivo', o dos historiadores. Só que este último não se revelou muito favorável; Carrara relata as dificuldades que teve para simplesmente localizar o material histórico. Acabou restringindo o seu trabalho a um único caso, por ele considerado o mais revelador.

A pesquisa histórico-bibliográfica, contida no segundo capítulo, revelou-se mais fácil e constitui-se em uma ótima síntese das idéias médicas sobre a relação crime-doença mental. Carrara começa discutindo a questão do aumento da criminalidade na passagem do século. Tanto na Europa (onde a figura de Jack, o Estripador, tornou-se paradigmática), como, em particular, no Brasil, verificou-se uma verdadeira onda de crimes. No caso europeu, fatores como a industrialização acelerada e a urbanização em precárias condições estavam em jogo; no caso brasileiro, havia, além disso, a liberação não planejada da mãode-obra escrava, a chegada dos imigrantes e a feroz competição trazida pela introdução de um mercado em moldes capitalistas. Formou-se, nas cidades, um "meio deliqüencial fechado", gerando a cultura do crime. Como hoje, a criminalidade era então um desafio que não se limitava apenas à questão da repressão: "Através do crime, juristas,criminalistas,criminólogos, antropólogos criminais, médicos-legistas, psiquiatras, todos fortemente influenciados por doutrinas positivistas ou cientificistas, di scutiam uma ques- 
tão política maior: os limites 'reais' e necessários da liberdade individual que, excessivamente protegida nas sociedades liberai s,era apontada como causa de agi tações sociais, ou, ao menos, como empecilho à sua re solução" (p. 65). Aos médicos, em particular (sobretudo aos alienistas), interessava o crime como subversão dos valores enrai zados na chamada natureza humana - o caso dos parrici das e infanticidas (p. 71). Um conceito emergirá então, principalmente entre os alienistas franceses: o da monomania, um delírio parcial, localizado ou circunscrito a apenas uma idéia: a piromania, a dipsomania eoutras. É de se notar que a modernidade trouxe de volta o espectro da melancolia, constantemente presente nas gravuras de Dürer e de outros mestres e também na famosa obra de Robert Burton, A Anatomia da Melancolia. Cabe, pois, perguntar se a mania não foi uma resposta à ameaça melancólica, sempre temida em sociedades competitivas (ver a popularidade do Prozac). Vem à mente o célebre episódio da 'tulipomania' na Holanda, em que pessoas ven diam até roupas para comprar - por al tíssimos preços - exemplares de tulipas; isso sem falar nas ondas especulativas maníacas, que se tornavam cada vez mais freqüentes.

Outro conceito muito importante era o da loucura moral (moral insanity), condição mórbida peculiar a certos indivíduos e que os acompanharia do nascimento à morte. Esses diagnósticos aumentavam o poder dos alienistas, mas colocavam-Ihes um problema: “...como curar algo quejá se delineia como fruto de um processo mórbido congênito ou hereditariamenteadquirido, quejá émuito mais uma condição anormal do queuma si tuação doentia?" (p. 77). A situação não melhorou quando o conceito de monomania foi substituído pelo de degeneração, introduzido em meados do século XIX por Morel, conceito este que enfatizava ainda mais a constituição inata e doentia de certos indivíduos. As lesões de ordem físico-natural ou sócio-moral - indo desde a constituição geológica do solo ao alcoolismo e ao deboche seriam transmitidas à descendência, conduzindo inevitavel mente à demência e à idiotia. "A degeneração claramente patologi za e medi cal iza o crime", diz Carrara (p. 97). Temos, então, a obra de Cesare Lombroso (1835-1909) que, baseada na antropometria e na cranioscopia, procurava identificar o criminoso nato, um conceito que, divulgado através do livro L'uomo Delinquente, teve enorme repercussão - Oswaldo Cruz, por exemplo, escreveu uma reverente missiva de apoio ao médico italiano. A avaliação da 'periculosidade' já não podia ser feita por juízes, mas dependia de uma avaliação antropométrica e psiquiátrica. Mais que isso, o júri popular deveria ser substituído por um corpo de especialistas. E, finalmente, "...o mani cômio judi ciári o se impôs como solução para os casos em que os acu sados eram considerados criminosos natos ou degenerados" (p. 125).

Voltamos, então, ao Manicômio Judiciário do Rio de Janeiro. Na terceira parte, adotando como modelo Michel Foucault em Eu, Pierre Rivière, que Degolei Minha Mãe, Minha Irmã e Meu Irmão, Sérgio Carrara estuda o caso de Custódio Alves Serrão, de 21 anos, que, em 1896, matou o sexagenário Belarmino Brasiliense Pessoa de M elo, uma cena de "Ioucura e sangue", segundo o jornal O País. A vítima era funcionário público e aparentemente não tinha família, mas agia como 'protetor' para Irene, irmã mais moça de
Custódio, que diariamente ia à casa dele. O criminoso, por outro lado, sentia-se, segundo a própria Irene, perseguido por Belarmino, que "queria dá-lo por louco". Depois de matar o sexagenário a tiros, Custódio matou também a empregada do homem, Andrônica Maria da Conceição, a qual, suspeitava de há muito, queria envenená-lo. Os médicos que o examinaram (e que não conseguiram submetê-lo ao exame antropométrico: Custódio não o permitiu) falavam em monomania e em degeneração. Custódio foi recolhido ao Hospício Nacional, fugiu, foi preso e levado de volta ao mesmo. A fuga precipitou um conflito envolvendo o Dr. Teixeira Brandão, responsável pela Assi stência Médico-Legal a Alienados no Distrito Federal. O médico, que queria introduzir uma administração dita científica no Hospício, havia retirado de lá (1890) as irmãs de caridade, a quem acusava de clientelismo na admissão de pacientes. A fuga de Serrão propiciou uma retaliação, inclusive por meio do Jornal do Brasil; Teixeira Brandão foi criticado por sua 'desadministração'. Se administração era sinônimo de enjaulamento, a acusação tinha algum fundamento, porque o médico reconhecia, de um lado, a "perversidadedo caráter e a au sência de senso moral" de criminosos e, de outro, preconizava que os hospícios não tivessem mais grades (no que se revelava bem superior ao alienista de Machado de Assis). Contudo, Teixeira Brandão não achava que Custódio fosse louco, e sim um criminoso comum; solicitou, pois, sua transferência para o presídio. Julgado, Custódio foi considerado louco e, apesar da oposição de Teixeira Brandão, de novo recolhido ao Hospício (a partir daí, Carrara não conseguiu mais localizar material a respeito do caso).

$\mathrm{O}$ affaire continuou provocando polêmica. Nina Rodrigues, do alto de seu prestígio, condenou Teixeira Brandão “por ter 'arrancado' do asilo um criminoso consi derado alienado eirresponsável" (p. 181). Na verdade, ambos tinham os mesmos conceitos sobre louco moral, degenerado e crimi noso nato, mas Brandão acreditava que, diferentemente dos alienados, "oscriminosos natos eram ou deveriam ser responsabilizados" (p. 182). Estas e outras discussões acabaram conduzindo à criação do Manicômio Judiciário, cuja pedra fundamental foi lançada em 1920.

Ao concluir, diz Carrara: “...tenho mais perguntas do querespostas" (p. 195). De um lado, "parece justo concluir que, ao serem levantados os muros do manicômi o judiciário, emparedava-se o conflito eaqueles sobre os quais ele se projetava"; por outro lado, o MJ, ambíguo e contraditório, "pareceter assegurado que as engrenagens da Justiça continuassem operando" (p.199). Seria, pois, um dispositivo prático que permite a vida em sociedades onde os homens são "Iivres e escravos, sujeitos e obj etos, inocentes e pecadores". Em suma: o Manicômio Judiciário sobrevive à sombra das nossas perplexi dades e de nossas incapacidades.

\section{Moacyr Scliar}

Departamento de Medicina Preventiva

Fundação Facul dade Federal de Ciências

Médicas de Porto Alegre 
EPIDEMIOLOGIA: CONTEXTOS E PLURALIDADE. Renato P. Veras, Maurício L. Barreto, $\mathrm{N}$ aomar de Almeida Filho \& Rita B. Barata (org.). Rio de Janeiro: Editora Fiocruz/Abrasco, 1998, 166 pp. ISBN 85-85676-54-X

A quarta publicação da Série Epidemiológica parece quebrar a perspectiva que vinha sendo adotada anteriormente na organização dos trabalhos oriundos do III Congresso Brasileiro de Epidemiologia, realizado em Salvador, BA, de 24 a 28 de abril de 1995. No volumel, são abordadas as relações entre eqüidade e saúde; no II , o eixo central é ocupado pelos aspectos teóricos da epidemiologia; no III, encontra-se a reflexão sobre a interface da epidemiologia com os serviços de saúde. O volume IV, denominado Epidemiologia: Contextos e Pluralidade, contém textos entre os quais o único liame existente talvez seja a abordagem de temas epidemiológicos ou que tenham interface com a epidemiologia. Uma 'moldura' para vários 'quadros'?

Tratando-se de um livro, o elo de ligação entre as partes é insuficiente para justificar a criação de ‘algo mais' que uma simples coletânea advinda da justaposição de textos singulares. A receita adotada é quase dadaísta. $\mathrm{O}$ 'cinturão de proteção' (lakatosiano?) expresso no subtítulo, Contextose Pluralidade, e a intenção dos organizadores contida na Apresentação do livro - "Propositadamente, os editores escapam aqui às defini ções temáticas em proveito da abertura do debate epidemiológi co à multidisciplinaridade, senão à verdadeira interdisciplinaridade" (p. 9) não convencem. O dadaísmo aparece quando se tenta construir algumas pontes entre os textos El iminação do sarampo no Brasil e Epidemi ol ogi a,desenvolvi mento tecnológi co eética; entre Avaliação nutricional deadul tos em estudos epidemi ológi cos e Subtipos deHIV-1 no Brasil; entre Epidemi ol ogia, Estatística, Filosofia e Matemática e Vigilância e meio ambiente: aspectos conceituais e metodológicos para áreas de mineração de ouro; ou ai nda entre Os Mídias ea mitifi cação das tecnol ogi as de saúde e Infecções parasitárias na pré hi stória da América do Sul. Nem interdisciplinar, nem transdisciplinar. Na realidade, multidisciplinar.

A sensação que fica é a de que os textos do volume IV foram selecionados após a organização dos três volumes anteriores: o que não foi enquadrado compôs o Epidemiologia: Contextos e Pluralidade, não havendo, portanto, um maior esforço para produzir uma coletânea cuja organização fosse mais rigorosa, mais estimulante. Nem sob forma de anais, os textos estariam adequadamente apresentados. Nas publicações referentes aos I ell Congresso Brasileiro de Epidemiologia, realizados, respectivamente, em Campinas, SP, em 1990, e em Belo Horizonte, MG, em 1992, mesmo sob a forma de anais, os textos obedecem a um enquadramento temático, ou teórico, ou metodológico etc. A 'moldura' talvez tenha prejudicado a apresentação do conjunto dos textos, embora obviamente não atinja o valor de cada um deles isoladamente.

Embora a publicação da obra não se justifique como tal, a leitura dos textos é salutar. Alguns deles tratam de esforços teóricos, metodológi cos e tecnológicos para enfrentar os desafios impostos pelo real: a grande variabilidade genética do HIV cria obstácuIos para o desenvolvimento de vacinas anti-HIV. Os textos Subtipos de HIV-1 no Brasil, de Ester C. Sabino, e As di ficul dades para o desenvolvi mento de vacinas anti-HIV ea participação brasileira nos ensaios clínicosfase I/II com vacinas candidatas, de Dirceu B. Greco, deparam-se, parodiando Goethe, com a "secura" da teoria diante da "preciosa árvore da vida". O mesmo pode ser dito sobre Epidemiologia, Estatística, FiIosofia eMatemática, de Cláudio J. Struchiner, M. Elizabeth Halloran, Robert C. Brunet \& Eduardo Massad, que analisa os pressupostos dos modelos de avaliação de eficácia de programas de intervenção para doenças infecciosas.

Se existem os próprios limites do conhecimento humano para que se solucione um problema num determinado período histórico, há também outros limites de natureza ética: novamente, a epidemia da Aids é o centro. Proteção vacinal e pensamento mágico: a controvérsia da vacina, de M ary Jane P. Spink, e Epidemi ol ogia,desenvol vimento tecnológico e ética, de Willian Saad Hossne, constituem exemplos de reflexão sobre liberdade (autonomia) e necessidade social no campo dos experimentos científicos. Os extremos da historicidade da doença são descritos ou analisados em I nfecções parasitárias na pré-história da América do Sul, de Adauto Araújo \& Luiz F. Ferreira, e Eliminação do sarampo no Brasil, de Elizabeth dos Santos.

No livro, são apresentados também textos sobre sistema de informação, vigilância epidemiológica, política de saúde, comunicação e saúde, epidemiologia e meio ambiente.

Um texto, A cultura da enfermi dade como fator de proteção e de risco, de Roberto Briceño-León, parece se sobressair entre os demais, pelo polêmico conteúdo. A concepção reducionista da cultura enquanto fator de risco poderá suscitar debates no campo interdisciplinar da epidemiologia e antropologia.

Em síntese, o leitor poderá abstrair a 'moldura' e apreciar os diversos 'quadros' que dela se destacam.

Djalma Agripino de Melo Filho

Secretaria de Saúde de Pernambuco

LECCIONES APRENDIDAS EN AMERICA LATINA DE MITIGACION DE DESASTRES EN INSTALACIONES DE SALUD - ASPECTOS DE COSTOEFECTIVIDADE. Departamento de Asuntos Humanitarios de las Naciones Unidas (DAH-NU) e Organización Panamericana de la Salud (OPAS). Washington, D.C.: OPAS, 1997, 116 pp.

ISBN 92-75-32217-1

O livro Lecciones Aprendi das en América Latina de Mitigación de Desastres en Instalaciones de Salud Aspectos de Costo-Efectividad, publicado pela Organização Panamericana de Saúde (OPAS) em conjunto com o Departamento de Assuntos Humanitários das Nações Uni das (DAH-NU), traz uma importante contribuição para os gestores na área da saúde na América Latina, particularmente daqueles de países em que há terremotos.

Para situar a importância do livro, deve-se antes contextualizar a importância dos desastres naturais na América Latina. Desai (1990), Glickman et al. (1992) e Alexander (1997) demonstram que a gravidade dos desastres naturais possui especial correlação 
com os níveis de riqueza dos países em que ocorrem, uma vez que, à medida em que os países são mais pobres, verifica-se um aumento na mortalidade por evento, sendo este o caso de muitos dos países de continentes como a África, a Ásia e a América Latina. Alexander (1997), por exemplo, tomando como referência os desastres naturais ocorridos no mundo entre os anos de 1977 e 1996, que resultaram em mais de mil óbitos ou mais de um milhão de dólares em perdas totais, demonstra que, do total de óbitos, $12,6 \%$ ocorreram nos países ricos, enquanto para os países pobres o total foi de $87,4 \%$. Nestes, além de os desastres serem muito mais severos em termos de conseqüências gerais, entre estas as mortes, el es afetam principalmente as populações mais pobres, revelando a fragilidade dos governos locais em estarem preparados para enfrentar esses eventos e reduzir seu impacto global, incluindo o número de vítimas fatais e não fatais (Desai, 1990).

Para agravar a situação, enquanto para os países ricos as perdas econômicas têm se situado em torno de $0,1 \%$ do Produto Interno Bruto (PIB), nos países mais pobres as perdas estão em torno de $2,0 \%$ do PIB, e, em alguns casos, como no do terremoto da Nicarágua, em 1972, as perdas econômicas atingiram algo em torno do PIB de um ano inteiro (Alexander, 1997). Deve-se ainda levar em conta que o quadro para os países pobres pode ser ainda mais grave, quando se considera que, para muitos dos desastres nestes países, não se encontra uma estimativa adequada do total dos impactos causados e das perdas econômicas.

De qualquer modo, o certo é que os desastres naturais, de um modo geral, representam elevados custos para os países que são afetados, sendo o seu impacto proporcionalmente muito maior nos países mais pobres, tanto em termos de vítimas - neste caso afetando principalmente as populações mais pobres -, quanto de perdas econômicas e impactos sociais globais.

Esse contexto fornece elementos para situar a gravidade do problema na América Latina, particularmente no que se refere ao setor saúde, quando se considera que aproximadamente $50 \%$ dos 15.000 hospitais existentes na região estão localizados em zonas de alto risco. Nos últimos 15 anos, um total de 93 hospitais e 538 centros de saúde, com uma estimativa de duzentas camas de capacidade instalada por hospital e dez camas por centro de saúde, foram sensivel mente danificados como conseqüência dos desastres naturais, sofrendo colapsos ou adquirindo condições vulneráveis que exigiram seu desalojamento, resultando na perda de aproximadamente 24.000 leitos. Estimando-se um custo médio de U\$ 130.000 por cama de hospital, as perdas acumuladas no período estariam em torno de U \$ 3.120.000.000 (OPAS/DAH-NU, 1997).

De acordo com o livro (OPAS/DAH-NU, 1997), em terremotos catastróficos, como os do Chile e do M éxico em 1985, como o do El Salvador em 1986 e o da Jamaica em 1988, cerca de $90 \%$ da capacidade instalada em matéria de hospitalização foram afetados. A elevada incidência de perdas na infra-estrutura de saúde se deve, em grande medida, ao fato de que a maioria dos hospitais da região são antigos e mesmo os mais modernos não contam com uma apli cação de rigorosos de códigos anti-sísmicos de construção. A carência de elementos de reforçamento e proteção preventiva tem contribuído para que, por vezes, somente um terremoto faça desaparecer uma seção completa de um hospital ou, em casos extremos, inabilitá-lo completamente. Além disso, um elevado número dessas instalações de saúde não possui programas de mitigação, planos de emergência ou infra-estrutura apropriada para resistir a eventos tais como furacões e terremotos.

Considerando que, em razão de suas características de ocupação, os hospitais merecem uma atenção especial na mitigação de desastres, já que, em seu interior, encontram-se pacientes em residência e tratamento, pessoal administrativo e visitantes, a OPAS iniciou, em 1990, um programa para estimular o incremento das instalações de saúde novas e das já existentes para que resistam aos desastres. Como parte dessa iniciativa, desenvolveu normas e projetos-piloto, apoiou análises de vulnerabilidade em hospitais e estudos de casos no Chile, Colômbia, Equador, Peru, Costa Rica, México e Venezuela, além de cooperar em esquemas de reconstrução de hospitais no M éxico. $O$ objetivo é disseminar a perspectiva de que, ao levar a cabo a planificação física de um hospital, os governos devem sempre ter em conta a vulnerabilidade das obras em face dos desastres naturais. Evita-se, assim, o desperdício de recursos financeiros e as repercussões políticas adversas provenientes da constatação pela população de que instalações de saúde foram parcialmente ou totalmente danificadas por causa da ausência dos investimentos necessários em infra-estrutura, planos de emergência e estratégias de mitigação das conseqüências.

É importante observar que o incremento das instal ações de saúde novas e das já existentes para que resistam aos desastres exige, necessariamente, que se invistam recursos financeiros. Contudo, o argumento desenvolvido logo no início do livro é de que a prática da aplicação da análise custo-benefício apresenta sérias limitações nesses casos, pois o que está em jogo são projetos que envolvem um serviço humano complexo, como é o caso dos serviços de saúde. As obras para redução de vulnerabilidade de hospitais têm por objetivo preservar vidas humanas e se expressam em programas sociais, sendo difíceis de traduzir em unidades monetárias. Em adição, levandose em conta a escassez de recursos financeiros na região, indubitavelmente esses programas competirão com outros de impacto social e também importantes, tais como educação e habitação, por exemplo. Acrescente-se a isto o fato de que nem todos os benefícios ou custos relacionados com preparativos e respostas para desastres são quantificáveis, particularmente quando se trata de expressar em termos monetários benefícios sociais, políticos e psicológicos que as obras de mitigação hospitalar podem trazer.

Tendo-se em consideração as dificuldades de se traduzir em cifras, tanto os custos, como os benefícios sociais, é desenvolvido no livro o argumento de que, para esse tipo de análise, a avaliação custo-efetividade é mais adequada do que a tradicional avaliação custo-benefício. Para este tipo de avaliação, a aceitabilidade é estabelecida quando os benefícios são maiores do que os custos do projeto. Já para a avaliação custo-efetividade, ainda que adote os mesmos princípios, a aceitabilidade de um projeto é estabelecida quando os custos investidos se traduzem em potencialidade de se alcançarem mais eficiente- 
mente os objetivos não possíveis de se expressar monetariamente, mas que se expressam em produtos, tais como número de consultas médicas de urgência ou de camas habilitadas em situações de desastres, por exemplo.

É uma importante contribuição o fato de o livro se basear em estudos de casos referentes a vários países da região, contando com informações sobre os aspectos relacionados às estratégi as seguidas em matéria de reforçamento da infra-estrutura de saúde, especial mente quando se considera que há, na região, ausência de um esforço unificado e uma política de visão regional que ressalte a importância de se reduzir o impacto dos desastres sobre as instalações de saúde.

Todavia, embora o livro tome como referência os estudos de desastres naturais que iniciaram a discussão sobre a vulnerabilidade de hospitais com base em uma ótica diferente, que incorpora o impacto social da perda de um hospital, deve-se considerar que, neste aspecto, é limitado. Como observa Alexander (1997), o conceito de vulnerabilidade tem estado intimamente relacionado a teorias de desenvolvimento e de eqüidade social (ou iniqüidade). Nesta perspectiva, tal conceito é chave para a compreensão dos desastres, pelo fato de estar correlacionado a uma perspectiva que aponta para a suscetibili dade de determinados grupos sociais, em determinadas regiões, de se tornarem as maiores vítimas de perdas e danos. $\mathrm{E}$ este é exatamente o caso da maioria dos países da América Latina.

Assim, o problema de se mitigar uma catástrofe e de se investir em infra-estrutura para os hospitais torna-se muito mais amplo, devendo estar associado às estratégias de promoção do desenvolvimento sustentável no nível local e instituindo medidas para aumentar a resistência das comunidades às perdas e danos associados à iniqüidade social e ambiental.

Carlos Machado de Freitas

Centro de Estudos da Saúde

do Trabalhador e Ecologia Humana

Escola Nacional de Saúde Pública

Fundação Oswaldo Cruz

ALEXANDER, D., 1997. The study of natural disasters, 1977-1997: some reflections on a changing field of knowledge. Disasters, 21:284-304.

DESAI, B., 1990. Managing ecological upheavals: a third world perspective. Social Scienceand Medicine, 30:1065-1072.

GLICKM AN, T. S.; GOLDING, D. \& SILVERMAN, E. D., 1992. Acts of God and Acts of Man - Recent Trends in Natural Disasters and Major Industrial Accidents. Washington: Resources for the Future.

OPAS/ DAH-NU (Organización Panamericana de la Salud/ Departamento de Asuntos Humanitarios de las Naciones Unidas), 1997. Lecciones Aprendidas en América Latina de Mitigación de Desastres en Instalaciones de Salud - Aspectos de Costo Efectividade. Washington: OPAS.
HACER FRENTE AL SIDA: PRIO RIDADES DE LA ACCION PUBLICA ANTE UNA EPIDEMIA MUN DIAL. Organización Panamericana de la Salud, Publicación Científica no 570. Washington, D.C.: OPAS, 1998, 432p.

ISBN 92-75-31570-1

Que medidas devem ser adotadas pelos governos dos países em desenvolvimento e pela comunidade internacional para enfrentar uma epidemia que já infectou, em duas décadas, aproximadamente trinta miIhões de pessoas e produziu seis milhões de óbitos?

$\mathrm{Na}$ busca de resposta para essa questão, o Banco Mundial, por meio deste informe traduzido para o espanhol pela OPAS, divulga informações e análises destinadas a auxiliar os encarregados de formular políticas, os especialistas em desenvolvimento e saúde pública e todos os envolvidos na estratégia pública de luta contra o HIV/Aids a elaborar um plano de ação eficaz para enfrentar a epidemia.

Estruturado em seis capítulos, o livro oferece um marco analítico destinado a priorizar intervenções governamentais de enfrentamento da epidemia nos países em desenvolvimento e, com base nele, recomenda uma estratégia ampla, passível de adaptação, de acordo com os recursos disponíveis e a etapa em que se encontra a epidemia em cada país. A análise está centrada principalmente sobre a economia do setor público, campo de conhecimento cujo objetivo central é avaliar vantagens e desvantagens associadas à distribuição de recursos públicos escassos. Além desse, dois outros campos de conhecimento - a epidemiologia do HIV e o controle de enfermidades desde o ponto de vista da saúde pública - são utilizados na abordagem do problema.

O primeiro capítulo - El Sida: un desafío para los gobiernos - traz informação básica sobre o HIV, a qual servirá de fundamento para o restante da obra. Inicialmente, apresenta-se ao leitor essa doença sexualmente transmissível, sintetizando as características biológicas do HIV, a evolução da infecção e os principais mecanismos de transmissão desse vírus. Mostra-se, ainda, o impacto na esperança de vida em países mais gravemente afetados, onde a Aids ameaça anular avanços, conquistados ao longo de décadas, na luta contra as doenças infecciosas. Analisa-se a carga de morbidade da doença nos países em desenvolvimento, onde as infecções pelo HIV constituirão uma fração cada vez maior do total de mortes por doenças infecciosas, afetando predominantemente adultos na etapa mais produtiva de sua vida. Nesses países, em 2020, o HIV/ Aids será a infecção de maior magnitude na mortalidade de pessoas de 15 a 59 anos, explicando metade de todas as mortes por causas infecciosas desse grupo etário. Além do impacto que a doença provoca na saúde, o informe destaca outras razões que justificariam o interesse de organismos de cooperação e fomento e de formuladores de políticas pela epidemia de HIV/Aids, tais como: a pobreza generalizada, a distribuição desigual de renda, a migração acelerada de trabalhadores, a urbanização rápida e a modernização cultural, que podem facilitar a propagação do vírus. Por outro lado, as mortes por Aids exacerbam a pobreza e a desigualdade que, por sua vez, podem ocasionar uma epidemia de maiores proporções, gerando um círculo vicioso. Nesse contexto, torna-se clara a necessidade de in- 
tervenção governamental, e, segundo o informe, a análise das bases para essa intervenção constitui o fundamento necessário para definir a forma de enfrentamento da epi demia de HIV/ Aids pelos governos. Uma série de argumentos são então apresentados para corroborar a função do governo na luta contra a Aids. Um deles, o el evado custo do tratamento da síndrome, em situações de recursos escassos, reforça a necessidade de investir na prevenção da infecção pelo HIV, desde os momentos mais precoces possíveis da epidemia: é mais barato prevenir do que tratar. Além disso, a Aids não tem cura e é quase sempre mortal. Atingindo adultos, impõe custos a outros membros da família e à sociedade, além de tornar as pessoas mais vulneráveis a contrair outras doenças infecciosas, como a tuberculose. A difusão de informação que capacite a pessoa a decidir se modifica ou não seu comportamento para diminuir as possibilidades de infecção é outra forte razão para a ação de governo, pois este possui os incentivos e a capacidade para gerar tal informação. O informe sustenta que a informação sobre o desenvolvimento da epidemia e sobre a forma de evitar a infecção constitui um bem público verdadeiro. Por último, os argumentos sobre direitos humanos enfatizam a obrigação governamental, reconhecida universalmente, de proteger as pessoas de danos infligidos por outras. A epidemia de HIV/ Aids torna necessária a participação dos governos para que as atitudes sociais e legais reconheçam os direitos dos indivíduos infectados e das pessoas saudáveis. Em que pese a força dos argumentos apresentados, normas e políticas sociais vigentes nos diversos países podem significar grandes desafios para o planejamento e a implementação de políticas sociais eficazes contra a enfermidade. Os problemas e suas respectivas soluções variam de um país a outro, mas o capítulo identifica e discute quatro situações comuns, a serem enfrentadas. São elas: a negação da epidemia do HIV/Aids, especialmente em sua fase inicial; a relutância em ajudar pessoas com comportamentos de risco a evitar a infecção; a preferência por ações moralistas e a pressão para destinar maiores recursos ao tratamento, em prejuízo dos necessários à prevenção.

O segundo capítulo - Enseñanzas estratégicas derivadas de la epi demiología del VIH - apresenta as diferentes trajetórias que a epidemia de HIV/Aids tem seguido nas diversas regiões do mundo. Como essas diferenças regionais podem ser apenas parcialmente explicadas pela introdução do vírus em momentos distintos, examinam-se os fatores biológicos e de comportamento que influem na propagação do HIV nas diversas populações. Assim, grande parte das variações observadas refletem disparidades nos comportamentos, tanto entre soci edades como entre os grupos dentro de cada sociedade, os quais, por sua vez, sofrem influência de inúmeros fatores sócio-econômicos e culturais. Com base nos conhecimentos produzidos no âmbito da epidemiologia do HIV/ Aids, discutem-se dois objetivos fundamentais a serem adotados pelos programas públicos destinados a reduzir a propagação do HIV. O primeiro é atuar o mais precocemente possível. Os governos podem conter a epidemia a um custo relativamente baixo, investindo em medidas de prevenção quando o número de pessoas infectadas ainda é pequeno. Mesmo em países onde há grande propagação do vírus, a adoção de medidas de prevenção eficazes podem salvar muitas vidas. O segundo objetivo é prevenir a infecção entre aquel es que estão mais expostos a contrair e transmitir o HIV, sustentado pelo efeito multiplicador que pode ser obtido pela modificação de comportamentos de alto risco. Finalmente, o capítulo descreve o nível e a distribuição da infecção pelo HIV nos países em desenvolvimento, classificando-os segundo três etapas da epidemia de HIV/Aids: 1) inci piente: quando a prevalência do HIV é inferior a 5\% nas subpopulações identificadas que supostamente têm um comportamento de alto risco; 2) concentrada: quando a prevalência é mai or do que $5 \%$ em uma ou mais das subpopulações supracitadas, mas a prevalência em mulheres atendidas por clínicas urbanas de atenção pré-natal ainda é inferior a 5\%; 3) generalizada: quando a disseminação do HIV se estendeu amplamente, além das subpopulações com comportamento de al to risco, e a prevalência em mulheres atendidas por clínicas urbanas de atenção pré-natal superou os $5 \%$.

Sustentando que, por meio de intervenções eficazes, as políticas oficiais podem influir nos comportamentos privados e íntimos que disseminam o HIV, o terceiro capítulo - Estrategias efi cientes y equi tativas de prevención del VIH/Sida - discute dois enfoques complementares: o primeiro busca influir diretamente nas decisões individuais dentro do marco econômico e social existente, mediante a modificação de custos e benefícios de al guns ti pos de comportamento; o segundo consiste em modificar as condições sócio-econômicas que dificultam ou impedem algumas pessoas de protegerem-se da infecção pelo HIV. Na perspectiva do primeiro enfoque, são examinados quatro tipos de políticas: 1 ) a oferta de diversos tipos de informação, uma vez que o conhecimento referente aos níveis de infecção pelo HIV e aos seus mecanismos de propagação e prevenção contribuem para diminuir o comportamento de risco, apesar de não serem suficientes e demandarem medidas adicionais; 2) a diminui ção dos custos do uso de preservativos, reduzindo seu preço, melhorando sua distribuição e estimulando sua aceitação social; 3) a redução dos custos de comportamento mais seguro no consumo de drogas injetáveis, por meio da diminuição de barreiras legais para aquisição e porte de equipamento esterilizado ou de programas de troca/ desinfecção de seringas e agulhas usadas; 4) aumento coercitivo dos custos de envolvimento no comércio sexual e de consumo de drogas injetáveis, com a ressalva de que procedimentos do tipo castigo e/ou proibição podem produzir efeitos incertos, como, por exemplo, aumento ao invés de diminuição dos comportamentos de risco. O segundo enfoque, cujos benefícios não se limitam à prevenção do HIV, mostra a aplicação de políticas indiretas para eliminar obstáculos sociais que impedem um comportamento de menor risco, tais como: a) a promoção de mudanças nas normas sociais, que favoreçam comportamentos menos arriscados, como, por exemplo, uma maior aceitabilidade do uso de preservativos; b) a melhoria da situação da mulher, por meio da educação e oferecimento de melhores oportunidades de emprego, garantindo seus direitos básicos e proibindo rigidamente a escravidão, a violação, o maltrato e a prostituição infantil; c) a redução da pobreza, aliviando os obstáculos econômicos que impedem o 
acesso dos pobres aos serviços básicos de prevenção do HIV.

Considerando as diversas possibilidades de intervenção discutidas, quais seriam as prioridades dos governos na prevenção do HIV/Aids? O informe propõe uma estratégia de prevenção ampla que maximize o impacto dos recursos oficiais destinados a conter a epidemia, remetendo a cada país a tarefa de identificar a combinação específica mais eficaz de programas, políticas e intervenções a serem adotadas. Destacam-se dois aspectos que, se levados em consideração, quase todos os governos podem meIhorar o grau de eficácia de suas medidas para evitar a propagação do HIV. O primeiro seria o aumento quantitativo e qualitativo da informação sobre: a natureza e a magnitude do comportamento sexual de risco e do consumo de drogas injetáveis na população; as tendências na incidência e prevalência do $\mathrm{HIV}$; os custos e efeitos de intervenções preventivas. O segundo aspecto consiste em utilizar essas informações para assegurar que os programas preventivos possibilitem a adoção de um comportamento mais prudente nas subpopulações mais expostas a contrair e disseminar o HIV, e em garantir o acesso dos pobres aos métodos de prevenção.

O quarto capítulo - Como afrontar el impacto del Sida - discute formas de mitigar o impacto da epidemia nas pessoas e na sociedade. Inicial mente, mostra-se que os governos de países com recursos escassos podem recorrer a formas factíveis, eficazes e humanas para ali viar os sofrimentos de pessoas infectadas pelo HIV. Nessa perspectiva, a utilização de medicamentos para aliviar sintomas e para tratar de infecções oportunistas pode diminuir, às vezes com baixo custo, o sofrimento e prolongar a vida produtiva dessas pessoas. $O$ trabalho reconhece a significativa melhora no estado de saúde de pessoas residentes nos países mais ricos em razão da utilização de terapia anti-retroviral, mas considera as dificuldades econômicas e operacionais para implementá-la nos países em desenvolvimento. Além disso, analisa as distintas opções de atenção e tratamento, concluindo que a assistência ini ciada em nível comunitário e domiciliar reduz drasticamente o custo da atenção e pode melhorar a quali dade dos últimos anos de vida dos pacientes com Aids. Na seqüência, o capítulo discute como os governos de países em desenvolvimento podem enfrentar tanto a maior demanda de assistência médica, quanto a escassez de atenção provocada pela epidemi a de Aids. Como esses governos têm, em geral, dificuldades para incrementar a proporção do gasto público em saúde e/ ou outorgar subsídios especiais para o tratamento do HIV/Aids, a linha de ação mais prudente, eficiente e eqüitativa seria situar o financiamento da atenção à saúde para o HIV/Aids no mesmo nível que o de outras enfermidades, zelando para que pacientes com enfermidades comparáveis e capacidades de pagamento similares gozem do mesmo acesso à atenção médica. $O$ trabalho sugere ainda a adoção de medidas humanitárias e factíveis em resposta à epidemia, tais como: difundir informação sobre a eficácia dos distintos tratamentos, subsidiar não só o tratamento de enfermidades oportunistas de tipo infeccioso e de doenças sexualmente transmissíveis, como também os custos de desenvolvimento de programas de controle de sangue para transfusão e de cuidado para os pacientes com Aids, e oferecer assistência especial aos pobres. Discutindo as formas como o HIV/Aids influi na pobreza e demonstrando que o impacto da doença é maior entre as famílias pobres, o estudo propõe uma estratégia para que os países em desenvolvimento empreendam medidas visando satisfazer as necessi dades dessas famílias afetadas pela epidemia, dentro do marco de outros programas contra a pobreza. Concluindo, recomenda-se aos governos que promovam a integração dos programas contra a pobreza com aqueles destinados a diminuir os efeitos da Aids, como forma de garantir que os recursos disponíveis cheguem aos locais onde são mais necessários.

Partindo da constatação de que as medidas nacionais e internacionais de luta contra Aids ainda estão muito distante de serem consideradas ótimas, o quinto capítulo - Esfuerzos conjuntos para hacer frente al Sida - ultrapassa as políticas nacionais examinadas nos capítulos anteriores para anali sar o modo como os principais atores no âmbito das políticas relativas à Aids (governos nacionais, organismos de cooperação e fomento bilaterais e multilaterais e organizações não governamentais) podem atuar conjuntamente para enfrentar a epidemia de forma mais eficaz. Assim, os governos nacionais têm como desafio definir sua função na luta contra a Aids, não de forma isolada e passiva, mas em colaboração com os outros atores, aproveitando ao máximo os pontos fortes de cada um. Reconhecen do a participação decisiva dos organi smos de cooperação e fomento no financiamento de políticas para Aids em quase todos os países em desenvolvimento, o trabal ho considera que os esforços serão mais eficazes se esses organismos mel horarem sua coordenação mútua e também com as autoridades nacionais, sem reduzir a velocidade com que oferecem assistência. Com a ressalva de que não se podem fazer generalizações quanto às funções que cada país deve assumir, a análise sugere que muitos governos nacionais e ONGs devem se encarregar de uma fração maior do financiamento das atividades preventivas, ampliando a responsabilidade desses governos no âmbito da vigilância epidemiológica e da prevenção. As ONGs freqüentemente desempenham a importante função de estimular os círculos oficiais a empreenderem ações necessárias e podem colaborar para que os governos ampliem seu raio de ação. Desse modo, os organismos financiadores poderiam se ocupar centralmente com a produção e difusão de conhecimentos e tecnologias, considerados bens públicos internacionais (por exemplo: a informação sobre medidas de prevenção e métodos de tratamento e a busca de uma vacina que se possa utilizar em países em desenvolvimento). Por último, esse capítulo discute, baseado em resultados obtidos por al guns países, formas de superação de obstáculos que impedem a implementação de uma política eficaz de combate à Aids. À medida que a epidemia evolui, muitos grupos com interesses conflitivos influem dinamicamente no desenho e aplicação dessas políticas. Portanto, os formuladores de políticas devem ter constante cuidado no esforço de empreender programas que redundem nos melhores interesses da população. Outro aspecto relevante enfocado pelo informe refere-se à cooperação de organismos bilaterais e multilaterais, a qual pode ser útil para fomentar o consenso público quanto a medidas eficazes e de baixo custo para enfrentar o HIV. Ademais, personali- 
dades que gozam de grande popularidade e que aderem à luta pública contra a epidemia podem provocar um enorme impacto positivo na consciência e nas atitudes da população. Enfim, embora os aspectos políticos da Aids variem muito de um local para outro, os países podem aproveitar sugestões de uma grande variedade de colaboradores e estabelecer com eles mecanismos de cooperação na busca da superação dos obstáculos encontrados.

O último capítulo - Enseñanzas del pasado y oportunidades para el futuro - resume as principais recomendações do informe e examina as oportunidades que os países têm de modificar o curso da epidemia em suas diferentes etapas.

A publicação e ampla divulgação desse livro é mais do que oportuna, considerando que, a cada dia, aproximadamente 8.500 pessoas contraem a infecção e que $90 \%$ dessas infecções ocorrem em países em desenvolvimento, onde a enfermidade já reduziu a esperança de vida, em alguns casos em mais de dez anos. De leitura agradável e fartamente ilustrado, o livro está destinado a líderes políticos, autoridades, especialistas, membros da sociedade civil e pessoas afetadas pelo HIV/Aids. Há nele informação essencial para o debate das prioridades da ação pública em face da epidemia, sem ser prescritivo. Desse modo, o trabalho configura-se como uma efetiva e importante contri buição para a construção de estratégi as eficazes de enfrentamento da Aids, considerando as especificidades de cada país.

Francisco de Assis Acurcio

Departamento de Farmácia Social

Faculdade de Farmácia

Universidade Federal de M inas Gerais 